\title{
Laboratory Evidence on the Effects of Sponsorship on the Competitive Preferences of Men and Women
}

\section{Citation}

Baldiga, Nancy R., and Katherine B. Coffman. 2018. "Laboratory Evidence on the Effects of Sponsorship on the Competitive Preferences of Men and Women." Management Science 64 (2) (February): 888-901. doi:10.1287/mnsc.2016.2606.

\section{Published Version}

$10.1287 / \mathrm{mnsc} .2016 .2606$

\section{Permanent link}

http://nrs.harvard.edu/urn-3:HUL.InstRepos:37221622

\section{Terms of Use}

This article was downloaded from Harvard University's DASH repository, and is made available under the terms and conditions applicable to Open Access Policy Articles, as set forth at http:// nrs.harvard.edu/urn-3:HUL.InstRepos:dash.current.terms-of-use\#OAP

\section{Share Your Story}

The Harvard community has made this article openly available.

Please share how this access benefits you. Submit a story.

Accessibility 


\title{
Laboratory Evidence on the Effects of Sponsorship on the Competitive Preferences of Men and Women
}

July 5, 2016

\begin{abstract}
Sponsorship programs have been proposed as one way to promote female advancement in competitive career fields. A sponsor is someone who advocates for a protégé, and in doing so, takes a stake in her success. We use a laboratory experiment to explore two channels through which sponsorship has been posited to increase advancement in a competitive workplace. In our setting, being sponsored provides a vote of confidence and/or creates a link between the protégé's and sponsor's payoffs. We find that both features of sponsorship significantly increase willingness to compete among men on average, while neither of these channels significantly increases willingness to compete among women on average. As a result, sponsorship does not close the gender gap in competitiveness or earnings. We discuss how these insights from the laboratory could help to inform the design of sponsorship programs in the field.
\end{abstract}

JEL codes: C91, D02 


\section{Introduction}

Professional service firms provide lucrative career opportunities for individuals with a desire to compete in technical fields such as accounting, law, engineering, and management consulting. Each year, these organizations recruit large classes of talented new associates to support the client service work of their managers and partners, with the goal of promoting the top talent to senior positions within the organization. However, employees face a variety of challenges as they pursue career advancement. Long hours, client demands, lack of work/life balance, limited access to positive role models and pressure to compete and win business are just a few of the factors that lead some professionals, especially women, to abandon the partnership track (see, Baldiga 2004, and related work on female advancement by Bertrand, Goldin, and Katz 2010, and Goldin 2014). As a result, women are often under-represented in senior roles. For instance, women have comprised almost 50\% of the entry cohort in the public accounting profession for more than two decades, but make up less than 20\% of firm partners (AICPA, 2015). ${ }^{1,2}$

Recently, sponsorship programs have been proposed as one way to address the gender gap in advancement. Sponsorship refers to a reciprocal relationship in which protégés form relationships with higher-level employees in their own firm or in other organizations. The sponsor serves to increase the visibility of the protégé, advocate for her career advancement, actively connect her to client and customer networks, and expand her perception of what she can do. The protégé, in return, aims to deliver exceptional performance, thereby promoting the legacy and reputation of the sponsor (Hewlett 2013). Hewlett argues that sponsors take an interest in their protégés “not out of altruism or like-mindedness” but "as an investment in his/her own career, organization or vision.” She asserts that "sponsorship, done right, is transactional” (Hewlett 2013). This is in contrast to the traditional mentorship model, in which mentors may serve as good listeners and coaches, but are not expected to advocate for their mentees or benefit professionally from their mentees’ success.

Through case studies, surveys and interviews, Hewlett (2013) and Foust-Cummings et al (2011) argue that women's advancement can be propelled by sponsorship. Anecdotal evidence suggests that there is value in the sponsorship programs offered by business organizations and professional service firms, improving participants’ assignments, compensation, confidence, and attitudes toward risk-taking and competition (Hewlett et al 2010). However, there remains a need for data on program efficacy.

\footnotetext{
${ }^{1}$ The most recent American Institute of Certified Public Accountants' report on trends in supply and demand indicates that women represented $48 \%$ of current accounting program graduates, but only $19 \%$ of accounting firm partners at public accounting firms with more than 50 employees. (AICPA, 2015).

${ }^{2}$ Women in corporate organizations face many of these same challenges. The 2015 study conducted by LeanIn.org and McKinsey \& Company suggests that women in corporate organizations face "greater barriers to advancement and a steeper path to senior leadership.” Their analysis suggests that at the current rate of progress, it will take twenty five years to reach gender parity at the senior VP level and more than one hundred years for C-Suite executives. See (http://womenintheworkplace.com/ui/pdfs/Women_in_the_Workplace_2015.pdf?v=5)
} 
Our contribution is to provide evidence on two key features of sponsorship programs: the fact that being chosen to be sponsored may serve as a vote of confidence and the linking of sponsor compensation to protégé performance. We use an incentivized laboratory experiment in order to study these two channels, taking advantage of the controlled environment of the laboratory to isolate each feature's effect on outcomes. This approach is a new contribution to the emerging literature on sponsorship.

Our goal is to explore whether sponsorship, in the form of votes of confidence and compensationtying, increases confidence and willingness to compete within the protégé cohort. Confidence and competitiveness are excellent proxies for many of the critical personal attributes and attitudes associated with career success (see discussions in Croson and Gneezy (2009), Gneezy et al (2003), Gneezy and Rustichini (2004), and NV (2007)). Controlled experiments have also provided evidence that competitiveness is a key predictor of career-relevant choices: Buser, Niederle, and Oosterbeek (2014) show that willingness to compete predicts the choice of university track among Dutch students, with more competitive individuals being significantly more likely to choose the more prestigious, higher return tracks of mathematics and science. Thus, we focus on a protégé's preference for competition as our outcome of interest. Following the literature, we define competitiveness in terms of willingness to enter a tournament, where payoffs depend upon relative performance.

Researchers have identified sizable gender differences in willingness to compete. Gneezy, Niederle, and Rustichini (2003) and Gneezy and Rustichini (2004) document that men outperform women in a competitive setting. And, Niederle and Vesterlund (NV 2007) find that women are significantly less likely than men to choose a competitive, tournament-based compensation scheme over piece-rate compensation. ${ }^{3}$ Gender differences in competitive attitudes have been suggested to contribute to female under-representation in the highest ranks of businesses and firms. Therefore, identifying institutional changes that can reduce the gender gap in competitiveness is of significant policy importance. Recently, researchers have begun to explore this area. Niederle, Segal, and Vesterlund (2013) and Balafoutas and Sutter (2012) find that affirmative action policies, in which there is a quota for the number of female winners of a tournament, can increase willingness to compete among women. Providing feedback to participants about their own and others' performance has also been shown to reduce the gender gap in competitiveness (see, Cason et al (2010), Ertac \& Szentes (2010), and Wozniak et al (2014)). Our work also serves as a contribution to this literature. We explore a new institutional change - the implementation of a sponsorship program - and ask whether it can reduce the gender gap in willingness to compete.

\footnotetext{
${ }^{3}$ Importantly, there is evidence that the gender gap in competitiveness is eliminated or reversed in female-typed tasks (see, Grosse and Riener (2010), Kamas and Preston (2010), Dreber, Essen and Ranehill (2011), and Shurchkov (2012)). However, since we will be using a math-based, male-typed task and our applications of interest are primarily male-typed domains, the existing evidence from male-typed domains is most relevant.
} 
Our framework will also allow us to explore how sponsorship impacts performance and compensation. There are a few potential reasons why sponsorship could drive improved performance. First, in treatments where the payoffs of sponsors and protégés are linked, there is an additional incentive to perform well: a better performance benefits not only the protégé, but also the sponsor. If a participant has other-regarding preferences such that she values generating additional earnings for another participant, this could lead to increased performance (see Cooper and Kagel (2015) for a survey of otherregarding preferences; see also Tonin and Vlassopoulos (2012, 2014) documenting that providing employees with social incentives can generate increased performance). Second, if sponsorship serves as a vote of confidence, participants may increase effort because they have more optimistic beliefs about the returns to this effort. The returns to increased effort are greater if a participant believes she may place in the top $25 \%$ of performers; therefore, if her believed probability of being in the top $25 \%$ of performers is increased by the sponsorship treatment, she may exert more effort, leading to better performance.

We find that sponsorship significantly increases willingness to compete among men, but that the effects of sponsorship are directionally smaller for women. Therefore, sponsorship fails to close the gender gap in competitiveness and earnings in the laboratory. We discuss these results as they relate to existing results on gender differences in competitiveness and analyze the policy insights they provide.

\section{Sponsorship: Institutional Background and Our Contribution}

The roots of sponsorship programs can be traced to the apprenticeship model from which many professional service firms evolved, where more experienced members trained and developed new staff. Through the years, partners served as informal sponsors for their hand-picked protégés. As the diversity of new staff increased, firm management recognized that partners tended to sponsor employees like themselves, leaving the increased number of female employees and employees of color without access to sponsors. ${ }^{4}$ Recently, major public accounting firms, professional service firms and businesses have formalized their sponsorship programs, matching sponsors with diverse, talented young professionals. ${ }^{5}$

\footnotetext{
${ }^{4}$ See http://blog.aicpa.org/2015/09/4-steps-to-developing-professionals-through-sponsorship.html\#sthash.YS2dxojl.dpbs for an illustration of how this history is typically presented. The PricewaterhouseCoopers sponsorship website notes "Evidence suggests that women and ethnic minority employees are less likely to have access to a sponsor on an informal basis - so we're targeting high potential female and ethnic minority directors and senior managers to match them with a suitable sponsor." See (http://www.pwc.com/gx/en/about/diversity/best-practices/pwc-sponsorship.html)

${ }^{5}$ Several of the large international public accounting firms offer sponsorship programs to their professional staff. Examples include Ernst \& Young (http://www.ey.com/US/en/About-us/Our-people-and-culture/Diversity-and-inclusiveness/A-recognizedcommitment-to-womens-leadership) and KPMG (http://www.kpmg.com/US/en/about/CSR/diversity-inclusion/Pages/developingdiverse-leaders.aspx) Many corporations also offer sponsorship programs. Each year Catalyst, a nonprofit organization that works to expand opportunities for women and businesses, recognizes companies for innovative and pioneering initiatives. These initiatives often include sponsorship programs. Examples of recent award winners include Chevron and Alcoa. See Catalyst Award Winners (http://www.catalyst.org/catalyst-award-winners).
} 
In some programs, members of Human Resources work with practice area leaders to create the sponsorprotégé pairings. Other professional service firms allow these relationships to develop organically.

Sponsorship extends the relationship between the executive and the protégé, as both parties have the opportunity to accrue benefits (or incur losses) from the relationship. Some of the payoffs involve enhancement of professional reputations, increased visibility, and opportunities within the organization. But, the payoffs may also be financial. Some programs include performance-tied compensation, where the sponsor earns additional compensation based upon the success of his or her protégé. ${ }^{6}$ Given this structure, it is likely that the sponsor will seek out protégés who are most likely to yield the highest returns to the sponsor. In this way, sponsorship may provide a vote of confidence for the protégé.

Our experiment focuses on these two aspects of sponsorship: the vote of confidence that being sponsored may provide and the linkage of protégé and sponsor compensation. In field data, it is difficult to separately identify the effects of these two features. In our laboratory study, we can isolate each feature, varying whether sponsors can choose their protégés, thus making it more likely that protégés view sponsorship as a vote of confidence, and whether sponsor compensation is linked to protégé performance. By disentangling these two features, we can better understand what drives outcomes in the field. ${ }^{7}$

An important question is what outcomes to focus on. Sponsorship programs are designed to help employees hone the leadership skills necessary to advance within the firm. ${ }^{8}$ Through sponsorship opportunities, employees’ develop not only their technical and communication skills, but also their willingness to compete and confidence. ${ }^{9}$ While we cannot study all the potential benefits to sponsorship in the laboratory, we can document the effect of our sponsorship interventions on willingness to compete and confidence. Firms recognize the importance of these attributes, as firm leaders must routinely compete for new engagements, negotiate with clients, present in high-level meetings, and assess the risk

\footnotetext{
${ }^{6}$ Organizations that report tying diversity goals and performance to compensation and bonuses include recent Catalyst Award Winners such as Chevron, Alcoa and KPMG. (See http://www.catalyst.org/catalyst-award-winners). A 2015 Wall Street Journal special section on Women in the Workplace featured an article in which several large companies have openly reported tying pay and performance to diversity and advancement goals. See (http://www.wsj.com/articles/more-companies-say-targets-are-the-keyto-diversity-1443600464)

${ }^{7}$ While others have explored the role of feedback in shaping competitive preferences, our vote of confidence is a different form of feedback - a noisy form of recognition that comes not from the experimenter but from an informed participant - that may more closely mirror the type of feedback available outside of the laboratory. We believe we are the first to study the paymenttying channel.

${ }^{8}$ Many professional service leadership development programs feature a sponsorship arrangement. See an example of a leadership development program offered at Deloitte (http://www.deloitte.com/view/en_US/us/About/Inclusion/leadershipdevelopment/index.htm). Organizations including the American Institute of Certified Public Accountants and the American Women's Society of Certified Public Accountants host conferences on leadership development. The fall 2015 Women’s Global Leadership Summit features a session on sponsorship.

${ }^{9}$ Hewlett writes "a sponsor helps you develop your executive presence, so that when those opportunities arise, you will be perceived as the undoubtedly right candidate”(Hewlett 2014). Hewlett et al found that male and female survey respondents rank “confidence” as the trait most highly associated with executive presence (Hewlett et al 2010).
} 
of pursuing particular business strategies. ${ }^{10}$ Furthermore, compensation is closely tied to willingness to compete for new business and outperform in the delivery of high quality services. ${ }^{11}$

Of course, we acknowledge limitations to studying sponsorship with a laboratory experiment. Perhaps most centrally, we capture data on a short-term experience. Thus, we are abstracting away from some of the benefits that accrue from these relationships in the field - for instance, access to professional networks or increased visibility. Despite these drawbacks, our setting provides an opportunity to study isolated aspects of sponsorship to determine if they are well-founded. A simple proof-of-concept that votes of confidence and payment-tying are effective in the laboratory could not only provide motivation for a larger-scale, more resource-intensive field evaluation, but also give policy-makers and firm leaders more confidence in the capacity for sponsorship programs to produce change in their organizations.

\section{Experimental Design}

Our experiment consists of four rounds and parallels NV (2007). In each round, participants have a four-minute period in which to complete as many addition problems as possible. Each addition problem consists of five two-digit numbers to sum. ${ }^{12}$ Participants do not receive feedback during the experiment. When a round ends, participants are simply told their time has expired; they do not learn of their absolute or relative performance. The incentive scheme varies by round.

Rounds 1 and 2: Baseline Measures of Performance Under Piece-Rate and Competition

In Round 1, participants earn 50 cents for every problem solved. In Round 2, payment depends on relative performance. Participants who place in the top 25\% of performers in that session earn $\$ 2.00$ for every problem solved. Participants who do not place in the top $25 \%$ of performers earn nothing.

\section{Round 3: Baseline Measure of Willingness to Compete}

In Round 3, participants make choices about how they would like to be paid for their Round 3 performance. The idea is similar to the tournament choice decision of NV (2007), but our implementation is slightly different. Rather than make a single choice of whether they would like to be paid according to a piece-rate incentive scheme (like Round 1) or a tournament incentive scheme (like Round 2), participants answer a series of questions about their willingness to compete depending upon the reward for winning

\footnotetext{
${ }^{10}$ In a 2014 article on the qualities of "Big 4 partners", Carter et al state, "Partners are driven, high energy people who exude selfconfidence" (Carter et al 2014).

${ }^{11}$ Professional service firms closely guard information about compensation models and metrics. In materials presented on its website for prospective employees, PricewaterhouseCoopers explains that recognition and rewards are associated with "highly exceptional discretionary effort and impact in providing internal and external client service that goes above and beyond the high expectations of your position." See (http://www.pwc.com/us/en/careers/campus/why-pwc/employee-benefits.html).

12 In the first four sessions, participants had a five-minute window in each round to complete addition problems. We reduced this amount of time in order to reduce average earnings, as participants in early sessions were earning well in excess of typical laboratory hourly rates. Our treatments are balanced along this dimension. For ease of reporting, for participants in the fiveminute window sessions, we compute a per minute score (correct problems solved/5) and multiply by four to approximate a score for a four-minute window.
} 
the tournament. Each question asks participants whether they would rather be paid according to Payment Scheme A -- 50 cents for every correct problem -- or Payment Scheme B - 0 if they finish in the bottom $75 \%$ of performers and " $\mathrm{B}$ " cents if they finish in the top $25 \%$ of performers. We vary " $\mathrm{B}$ ” from 100 cents to 300 cents, in increasing increments of 25 cents, creating nine binary choices.

By using a sequence of binary questions, we can be more precise about the gender gap in competitiveness. We can explore whether the gap varies with the tournament reward, and we can ask how much additional compensation is needed to induce a woman to compete (relative to a man). This small design change increases the amount of information available to the researcher without adding a substantial amount of time to the procedure. Other researchers have advocated similar approaches. The elicitation closest to ours is that of Petrie and Segal (Working paper), who implement a very similar procedure to ours, asking participants to make a series of binary decisions between a fixed piece-rate and varying tournament prize wages. In Ifcher and Zarghamee (2014), participants make a series of binary decisions between a fixed tournament pay option and various piece-rate wages (from 0 to $100 \%$ of the tournament wage); Gneezy and Pietrasz (2015) propose and test a linear measure of competitiveness that asks participants to choose how much of their payment will be determined by a competitive scheme.

In our experiment, prior to making their decisions, the participants are told that one of the nine questions will be selected and implemented to determine their payment for Round 3. After they make their decisions but before they complete their addition problems, the selected question is revealed; this eliminates any uncertainty about what incentives they are facing when they perform in Round 3 . We employ the design from NV (2007) and compare Round 3 performance to the Round 2 performances in order to determine payments. That is, participants who choose to compete in Round 3 are competing against the Round 2 performances of everyone in that session. This minimizes the extent to which otherregarding preferences could influence payment scheme decisions. It also eliminates any uncertainty as to the set of fellow competitors. This procedure is explained to participants.

Before they complete their addition problems, participants are asked to make an incentivized guess about their Round 3 performance. They are asked to indicate whether they believe their Round 3 performance will put them in the top 25\% of Round 2 performers, $25 \%$ - $50 \%$ of performers, 50 - $75 \%$ of performers, or bottom $25 \%$ of performers. Participants receive an additional $\$ 0.25$ if they guess correctly. Treatment Intervention

Our intervention occurs after Round 3. Our goal is to explore how decisions and performance in Round 4 are impacted by being sponsored. We have three versions of sponsorship:

- Payment-Tying (PT): protégé choices and performance determine the compensation of a sponsor

- Vote of Confidence (VOC): protégés are chosen by sponsors, rather than randomly-assigned

- Vote of Confidence and Payment-Tying (VOCPT): both Vote of Confidence and Payment-Tying 
We compare behavior under these treatments to the behavior of participants who are not sponsored.

In our vote of confidence treatments, we use participant sponsors who make incentivized choices over who they would like to sponsor and we vary which participants are made available to these sponsors as potential protégés. By varying which protégés are made available, we are able to address the selection problem: rather than participants of only high ability being assigned to sponsorship, participants of a wide range of abilities are sponsored. But, it also means that participants who are chosen will not receive a clear, credible signal of whether they are of high ability. Instead, being chosen may serve as a "vote of confidence”, a noisy form of feedback that provides encouragement or support.

While our "vote of confidence" treatment does not resemble typical experimental feedback interventions (i.e. there is an X\% chance you are in the top $25 \%$ of performers), we believe there is value in studying this less informative version of feedback. Outside of the laboratory, feedback is unlikely to contain precise information about ability; instead, feedback may arrive in the form of encouragement, messages of support, or being chosen for a special assignment, promotion, or team. Our "vote of confidence" treatments come closer to these versions of feedback, and our focus will be on gender differences in how participants respond to them. We explain this design in detail below.

\section{Sponsors}

Three individuals per session are randomly-selected as Sponsors. ${ }^{13}$ Sponsors are told that they will earn \$0.25 per correctly solved problem for each protégé who both (a) ranks among the top 25\% of performers (again, relative to Round 2 performances) and (b) chooses Payment Scheme B (the tournament option). ${ }^{14}$ Sponsor-protégé pairing rules vary by treatment and are explained below.

\section{Payment-Tying Treatment}

We randomly assign participants to the PT treatment at the session level. In a fourth of our sessions, we randomly assigned every participant in the lab to a sponsor. These pairings were then communicated to sponsors. Sponsors were provided with a list of the participants in their session that they had been selected to sponsor (identified by participant numbers). Participants are told that they have been randomly assigned to a sponsor. This is an exogenous pairing of protégés and sponsors; thus, being sponsored here arguably does not serve as a vote of confidence.

\section{Vote of Confidence and Vote of Confidence \& Payment-Tying Treatments}

For the other two sponsorship treatments, we do not use pure random assignment. This is because we would like being chosen to be sponsored to provide some form of a vote of confidence in these treatments. For the VOC and VOCPT treatments, we ask sponsors to make incentivized decisions about

\footnotetext{
${ }^{13}$ In two sessions, there was only one sponsor due to the fact that these sessions contained fewer than 12 total participants.

${ }^{14}$ Note that there are nine decisions between Payment Schemes A and B for protégés; to determine sponsor payoffs, we look only at the protégé's choice on one of these questions (the one of the nine that is selected to determine payments for Round 4).
} 
who they would like to sponsor. Sponsors make a series of pairwise decisions between participants. In each decision, they are provided with the Round 1 and Round 2 scores of the participants. For instance, a sponsor might be asked to make a decision between the following two participants:

Participant \# 202

\begin{tabular}{|c|c|}
\hline Round 1 Score & Round 2 Score \\
\hline 7 & 11 \\
\hline
\end{tabular}

Participant \# 217

\begin{tabular}{|c|c|}
\hline Round 1 Score & Round 2 Score \\
\hline 5 & 9 \\
\hline
\end{tabular}

In each session, the experimenter ranks all participants according to total number of problems solved in Rounds 1 and 2. Then, she follows a fixed algorithm for generating the set of pairwise choices each sponsor faces. The algorithm is aimed at achieving a similar distribution of abilities among those in the sponsorship treatments and those in the Unsponsored treatment. To do so, the algorithm withholds some high ability individuals - that is, some high ranking individuals never appear in any pairwise decision, assuring that they are assigned to the Unsponsored treatment. In addition, the algorithm pairs participants strategically: for instance, the algorithm might pair the $14^{\text {th }}$ best individual with the $6^{\text {th }}$ best individual, making it unlikely that the $14^{\text {th }}$ best individual will be sponsored, while pairing the $15^{\text {th }}$ best individual with the $23^{\text {rd }}$ best individual, making it likely that the $15^{\text {th }}$ best individual will be sponsored. In this way, the $14^{\text {th }}$ and $15^{\text {th }}$ best individuals, likely to be of similar abilities, are almost surely assigned to different conditions. The algorithm and further discussion of this procedure are in Online Appendix I.

After sponsors make their decisions, a coin is flipped. If the coin is heads, sponsors earn payment based upon the performance and choices of their protégés (generating the VOCPT treatment). If the coin is tails, sponsors instead earn a fixed payment for Round 4 (generating the VOC treatment). Therefore, conditional on selection into one of the VOC treatments, the assignment to the VOCPT treatment is random. Furthermore, because sponsors know it is always the case that the performance of their protégés may determine their earnings at the time of their decisions, sponsors are incentivized to choose the protégé within each pair that they feel is most likely to maximize their earnings.

This algorithm combined with the choices of the sponsors assigns some participants within a session to the VOC treatment, some to the VOCPT treatment, and some to the Unsponsored treatment. Participants in the Unsponsored treatment were either never presented to a sponsor as a possible choice (due to the algorithm), or were presented to a sponsor but not chosen. In Section V.B, we investigate whether the distributions of abilities across the treatments are similar despite the possibility of selection.

After the sponsors make decisions, we transmit the information to the other participants with a handout. ${ }^{15}$ The key language in the three treatment handouts varies as follows:

\footnotetext{
15 The full text of each handout is provided in our Online Materials Appendix.
} 
- PT: "Someone was randomly assigned to be your sponsor and their payment depends upon your performance."

- $\quad$ VOC: "Someone has chosen to sponsor you, but the coin flip determined that their payment does not depend upon your performance.”

- VOCPT: "Someone has chosen to sponsor you and the coin flip determined that their payment depends upon your performance.”

In every session, every individual in the room (other than the sponsors) receive a handout. Note that individuals in the Unsponsored treatment are not told that they were not sponsored. Like the participants in other treatments, they are told that three people in the room have been selected as sponsors and will not complete problems in Round 4. But, they are not given any additional information about the sponsors. Therefore, we interpret our Unsponsored data as representing the effect of no sponsorship program, not as representing the effect of a sponsorship program on those who are not sponsored. Of course, it may have been the case that these participants assumed from the lack of information that they had not been sponsored. We cannot rule this out with this design. However, we later ran an additional control treatment with no sponsors or sponsorship (all participants simply proceeded directly from Round 3 to Round 4), in order to verify that our interpretation is valid. These results are presented in Online Appendix V. We find no significant differences between our Unsponsored treatment and this alternative control treatment.

Participants in the VOC treatments are not told about the choice structure that the sponsors faced. Their handout reads "Sponsors were told that their payment might depend on the performance of the people they chose to sponsor. They were given subject numbers and performances from Rounds 1 and 2 and had to choose whom to sponsor. Then, the computer flipped a coin to determine whether they would receive a fixed payment or their payment would depend upon the performance of their chosen protégés." This language makes it clear that sponsors were incentivized to choose higher-performing participants. But, it does not make it clear how many participants sponsors chose, or from what size group. Thus, being chosen is not a signal of being high ability, but rather a less precise statement of support or backing. We do not make predictions about how much participants should update their beliefs in response to this signal. Instead, our focus is on making clean across gender comparisons within these treatments.

\section{Round 4: Willingness to Compete}

After distribution of the handouts, Round 4 proceeds exactly as Round 3. We elicit willingness to compete using the same nine binary questions, again explaining that one will be randomly selected to determine payment for that round. We also use the same belief elicitation after their willingness to compete decisions, before they complete the addition problems. Following completion of Round 4, participants are asked to answer demographic questions.

\section{Implementation}


The experiment was conducted at the Harvard Business School Computer Laboratory for Experimental Research. We ran 12 sessions with 354 participants from March 2014 - June 2014. Sample sizes are displayed In Table 1. Sessions ranged in size from 11 to 36 participants, with the median session size being 36 participants. The share of women in each session ranged from $30 \%$ to $63 \%$, with the median share of female participants being 53\%. Participants are paid a \$10 show-up fee and earnings from one randomly-selected round. Average earnings were \$25 and all sessions were finished in less than one hour.

Table 1. Number of Men and Women by Treatment

\begin{tabular}{lccc}
\hline Treatment & Men & Women & Total \\
\hline Sponsor & 18 & 14 & 32 \\
Unsponsored & 51 & 41 & 92 \\
VOC & 31 & 41 & 72 \\
Payment-Tying & 36 & 39 & 75 \\
Vote of Confidence + Payment-Tying & 40 & 43 & 83 \\
Totals & 176 & 178 & 354 \\
\hline
\end{tabular}

\section{Empirical Approach}

Our goal is to identify the impact of the treatments on competitiveness, performance, and earnings. We call the lowest tournament wage at which the participant preferred the tournament to the piece rate payment scheme the participant's cutoff for a round and we use this as our measure of willingness to compete. ${ }^{16,17}$ Note that a larger cutoff indicates a lower willingness to compete, as this means it required a larger tournament wage to induce the participant to compete. We measure performance as number of problems solved correctly in a round. We calculate earnings within a round by averaging over what earnings would have been for each of the nine decisions a participant made. ${ }^{18,19}$

We ask how Round 4 cutoffs, performance, and earnings vary across treatment, and we take advantage of the fact that we have Round 3 observations for each participant collected under identical conditions. Thus, we use the following regression specification:

$$
y_{\text {Round } 4}=\beta_{0}+\beta_{1} * \text { VOC }+\beta_{2} * P T+\beta_{3} * \text { VOCPT }+\beta_{4} * y_{\text {Round } 3}+\bar{\beta} * \text { Controls }+\epsilon
$$

\footnotetext{
${ }^{16}$ If a participant never chose the tournament scheme, we code that as a cutoff of 325 cents (an additional 25 cent increment above our maximum value of 300 cents).

${ }^{17}$ We define the cutoff by the lowest wage at which the participant accepted the tournament wage even for participants who were non-monotonic in their decision-making - i.e. those who accepted the tournament at some wage $\mathrm{X}$ and then switched back to preferring the piece rate at some wage $Y>X$. Only $6 \%$ of participants in Round 3 and $4 \%$ of participants in Round 4 indicated non-monotonic preferences. The results are unchanged if we exclude these participants.

${ }^{18}$ For instance, a participant who had a cutoff of 200 cents in Round 3, completed 10 problems correctly, and ranked in the top $25 \%$ of performers would have earnings equal to: $(50 * 10+50 * 10+50 * 10+50 * 10+200 * 10+225 * 10+250 * 10+275 * 10+$ $300 * 10) / 9=1611$ cents. If that participant had placed outside of the top $25 \%$ of performers, she would have earnings equal to: $(50 * 10+50 * 10+50 * 10+50 * 10+0+0+0+0+0) / 9=222$ cents.

${ }^{19}$ For ease of reporting, for participants in the five-minute window sessions, we compute a per minute score (correct problems solved/5) and multiply by four to approximate a score for a four-minute round. Similarly, we compute a per minute earnings measure (earnings/5) and multiply by four to approximate earnings for a four-minute round.
} 
where $y$ refers to the outcome of interest - either cutoff, performance, or earnings - and VOC, $P T$, and VOCPT are treatment dummies. Our vector of controls consists of all information we collected in the demographic section of the experiment as well as participant scores in Rounds 1 - 3.

\section{Results}

A. Baseline Willingness to Compete Results

In Table 2, we provide summary statistics for the participants. While men and women in our sample were of similar ages, there are some directional differences between these sub-samples: more men than women were currently undergraduates, fewer men than women were humanities majors $(\mathrm{p}<0.05)$, and, most importantly, there are marginally significant differences in their ability on the number adding task, both under piece rate (Round $1, \mathrm{p}=0.07$ ) and under forced competition (Round $2, \mathrm{p}=0.09$ ). In the analysis that follows, we will control for both these demographic and performance differences.

Table 2. Summary Statistics

\begin{tabular}{llll}
\hline & Men & Women & p value \\
\hline Avg. Year of Birth & 1991 & 1991 & 0.96 \\
Proportion Undergraduate & 0.75 & 0.67 & 0.12 \\
Humanities Major & 0.17 & 0.26 & 0.04 \\
Social Science Major & 0.35 & 0.37 & 0.72 \\
Math Major & 0.14 & 0.10 & 0.18 \\
Science Major & 0.25 & 0.26 & 0.86 \\
Have Played Competitive Sport & 0.86 & 0.75 & 0.009 \\
Avg. Score 1 (Problems/Round) & 9.36 & 8.71 & 0.07 \\
Avg. Score 2 (Problems/Round) & 10.31 & 9.61 & 0.09 \\
Avg. Score 3 (Problems/Round) & 10.97 & 10.01 & 0.028 \\
Avg. Score 4 (Problems/Round) & 11.67 & 9.99 & 0.0003 \\
Avg. Session Size & 32.30 & 32.58 & 0.69 \\
Avg. Share Female in Session & 0.49 & 0.52 & 0.002 \\
Session with 4 Minutes to Solve & & & \\
Problems & 0.56 & 0.62 & 0.24 \\
N & 176 & 178 & \\
\hline
\end{tabular}

We begin by documenting the gender gap in willingness to compete in the Round 3 baseline. We replicate the results of NV (2007), finding that, on average, men are more willing to compete than women. Because of our elicitation, we can describe the gender gap in more detail (see Figure 2). A smaller fraction of women than men choose the tournament for every tournament wage, and this difference is significant for tournament wages of 150, 175, 200 (the tournament wage in NV), and 300 cents. We observe the largest gap in willingness to compete for a tournament wage of 150 cents: at this 
wage, $50 \%$ of men and $33 \%$ of women choose to compete ( $<<0.001$ from two-tailed two-sample test of proportions). We find that men have an average cutoff of 186 cents and women have an average cutoff of 202 cents ( $p=0.051) .{ }^{20}$ We can also estimate the difference in Round 3 cutoffs between men and women from a regression that controls for their ability in the first two rounds. We estimate that, conditional on measured ability, women provide cutoffs approximately 16 cents greater than men on average $(\mathrm{p}=0.04)$.

Men also solve more problems in Round 3 than women do: 10.97 versus 10.01 on average $(p=0.03)$. Average earnings for men are 1125 cents and average earnings for women are 794 cents (difference $=331$ cents, $\mathrm{p}=0.009$ ). If we control for the number of problems solved, women still earn on average 103 cents less than men (difference is not significant, $\mathrm{p}<0.17$, estimated from OLS regression). This indicates that roughly a third of the earnings gap is driven by differential entry into competition.

\section{Willingness to Compete in Round 3}

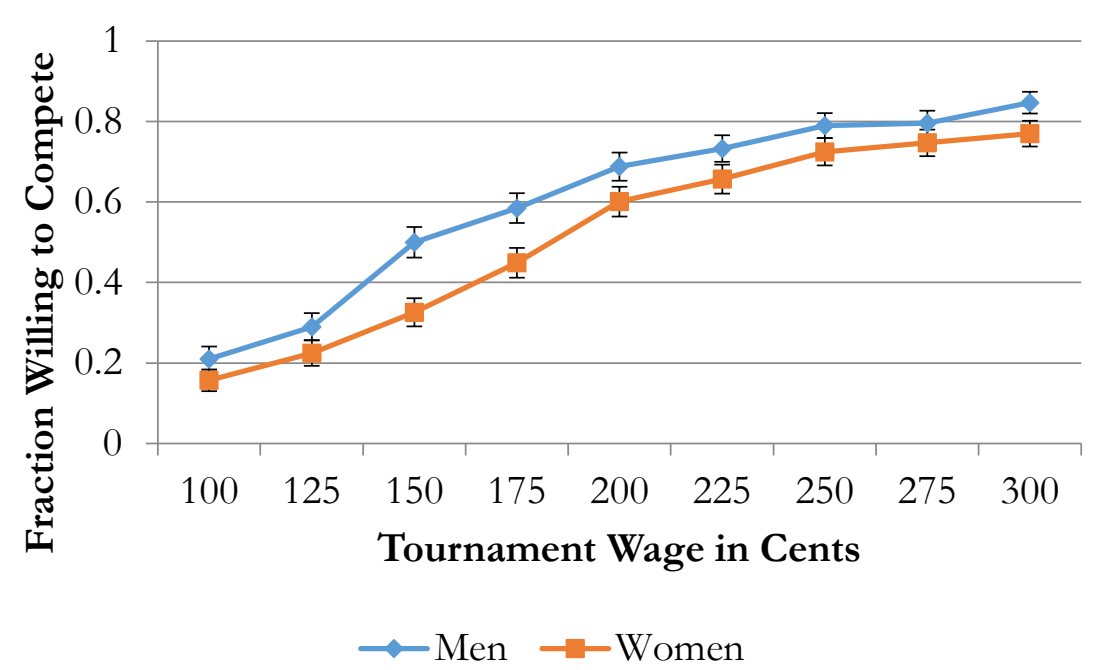

Figure 2. Willingness to Compete in Round 3

Standard error bars shown.

\section{B. Exploring the Ability Distributions by Treatment}

Before exploring the effect on sponsorship on willingness to compete and performance, we verify that our assignment procedure created similar distributions of ability across the treatments. Participants are assigned to the VOC and the VOCPT treatments if they are chosen by a sponsor. Participants who are not chosen in those sessions, either because they were not presented as a possible option or because they were presented but were not selected by a sponsor, are assigned to the Unsponsored treatment. Thus, selection has the potential to impact the distribution of ability across these treatments.

\footnotetext{
${ }^{20}$ Unless explicitly stated otherwise, p-values are generated by two-tailed Fisher-Pitman permutation tests comparing distributions and testing the null of equality.
} 
Participants complete three rounds of problem-solving before our intervention; thus, we consider sum of scores in first three rounds as our measure of pre-treatment ability. ${ }^{21}$ Average ability is indistinguishable across the Unsponsored, PT and VOC treatments. Participants in the Unsponsored treatment solve on average 29.3 problems in the first 3 rounds (SD 13.05); participants in the VOC treatments solve 29.9 problems (SD 8.79); and, participants in the PT treatment solve 30.0 problems (SD 10.04). We cannot reject the null of equality of means or distributions in any pairwise comparison of the treatments. ${ }^{22}$ Across treatments, there is also a similar fraction of individuals who placed among the top $25 \%$ of performers in Round 3 (relative to Round 2), indicating that they stand to gain from competing. ${ }^{23}$

However, the Unsponsored treatment, relative to our Sponsorship treatments, has higher variance in total performance, with some low and high outliers. We can use a two-sample Kolmogorov-Smirnov test to compare the shapes of the distributions. While the PT distribution is not significantly different from the Unsponsored distribution ( $p=0.29$ ) or the VOC distribution ( $p=0.97$ ), we observe a marginally significant difference between the Unsponsored distribution and the VOC distribution ( $\mathrm{p}=0.09$ ).

In the analysis that follows, we are careful to control for ability in all of our specifications. We also present analysis in Online Appendix VI that shows that our results are robust to other approaches to controlling for ability, including using score fixed effects and using only participants from the middle $90 \%$ of the ability distribution. Finally, in Online Appendix II, we run a placebo test. Instead of predicting Round 4 decisions from our treatment assignment, we predict Round 3 decisions, which occur preintervention. If selection on ability drove our main results, we would expect similar effects of our treatments on Round 3 and Round 4 decisions; we find no evidence that this is the case.

\section{How Sponsorship Impacts Willingness to Compete}

We now ask how our sponsorship treatments impact participants’ willingness to compete. Specifically, we look at how competitiveness changes between Rounds 3 and 4 for a given participant. We start by exploring the data graphically. In Figure 4, we show the fraction of men and women willing to compete at each tournament wage in Round 4 for each treatment: Unsponsored, VOC, VOCPT, and PT. Each of the sponsorship treatments increases willingness to compete among men at every wage relative to the Unsponsored treatment. The effect of the sponsorship treatments for women is more mixed.

\footnotetext{
${ }^{21}$ In Online Appendix Section III, Figure A1, we graph the distribution of total performance by treatment, comparing the Unsponsored treatment, both VOC treatments, and the PT treatment. We also replicate this entire section using sum of first two scores rather than sum of first three scores. The results are unchanged.

${ }^{22}$ Two-tailed t-test pairwise p-values: Unsponsored v. VOC, p = 0.70; Unsponsored v. PT, p = 0.69; VOC v. PT, p = 0.90. FisherPitman permutation tests: Unsponsored v. VOC, $\mathrm{p}=0.70$; Unsponsored v. PT, p = 0.69; VOC v. PT, p = 0.90; Mann-Whitney ranksum tests: Unsponsored v. VOC, $\mathrm{p}=0.26$; Unsponsored v. PT, $\mathrm{p}=0.37$; VOC v. PT, $\mathrm{p}=0.97$

${ }^{23}$ Prior to our intervention, 35\% of Unsponsored participants would win the tournament prize in Round 3. The corresponding percentage in our sponsorship treatments is $34 \%$ in the VOC and VOCPT treatments and $28 \%$ in the PT treatment. None of these across treatment differences are significant.
} 

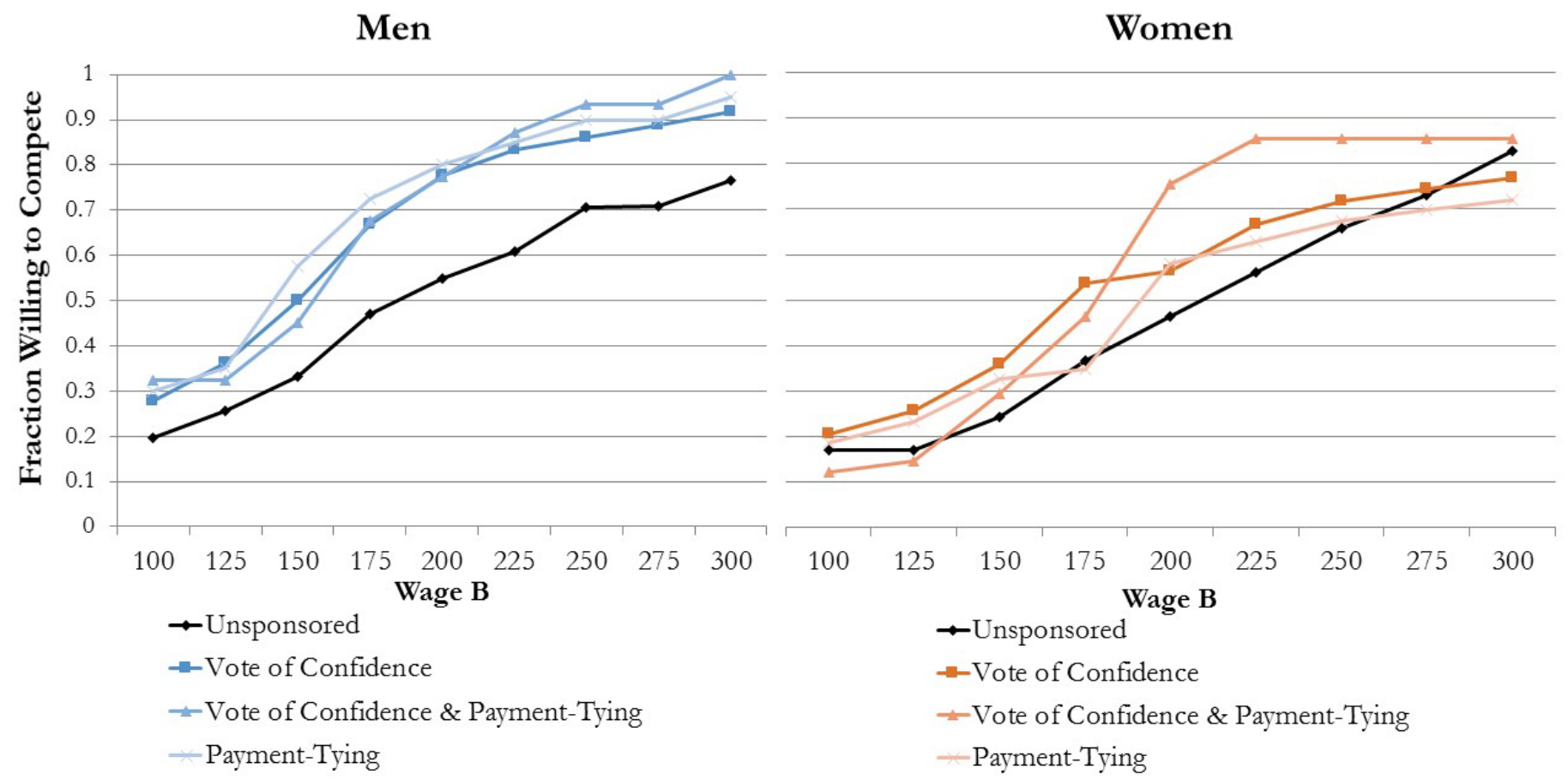

Figure 4. Fraction of Men and Women Willing to Compete in Round 4 at Each Wage

We can use regressions to quantify these changes in willingness to compete precisely. In Table 3, we estimate the impact of our treatments on cutoff in Round 4. In Specification I, we predict a participant's cutoff in Round 4 from her treatment assignment, whether the participant is female, cutoff in Round 3, believed rank in Round 3, and scores in Rounds $1-3$, leaving out demographic controls. In Specification II, we add in our controls: whether or not the participant is a current undergraduate, year of birth, major, and whether the participant has played competitive sports. In both specifications, we see a significant impact of each of the three sponsorship treatments. Relative to the Unsponsored treatment, the VOC treatment increases willingness to compete by 21 cents, the VOCPT treatment increases willingness to compete by 26 cents, and the PT treatment increases willingness to compete by 20 cents. We cannot reject that all three treatments have the same effect on willingness to compete.

In Specification III, we explore whether the treatments impact men and women differently. The analysis shows that all three treatments are directionally less effective for women than men. All sponsorship treatments are estimated to increase willingness to compete among men by approximately 32 cents relative to the Unsponsored treatment, and each of these effects are significant. However, none of the sponsorship treatments are estimated to have a significant impact on women's willingness to compete. The directional effects are an increase in willingness to compete (relative to the Unsponsored treatment) of 9 cents in the VOC treatment (SE 11.3, p=0.43), 18 cents in the VOCPT treatment (SE 11.1, p=0.10), and 6 cents in the PT treatment (SE 11.2, p=0.60). While we cannot statistically distinguish the impact on 
men from the impact on women of the VOC and VOCPT treatment, we can marginally reject the hypothesis that men and women are similarly impacted by the PT treatment $(\mathrm{p}<0.10)$.

Table 3. Regression Analysis of Willingness to Compete in Round 4

\begin{tabular}{|c|c|c|c|c|}
\hline & \multicolumn{4}{|c|}{ OLS Predicting Cutoff in Round 4} \\
\hline Specification & I & II & III & IV \\
\hline \multirow[t]{2}{*}{ VOC } & $-20.4 * * *$ & $-21.3 * * *$ & $-32.2 * * *$ & $-13.1^{*}$ \\
\hline & $(7.65)$ & $(7.82)$ & $(10.8)$ & $(7.32)$ \\
\hline \multirow[t]{2}{*}{ VOCPT } & $-25.0 * * * *$ & $-25.6 * * * *$ & $-31.5^{* * *}$ & $-18.7 * *$ \\
\hline & $(7.74)$ & $(7.90)$ & $(11.4)$ & $(7.37)$ \\
\hline \multirow[t]{2}{*}{ PT } & $-17.5^{* *}$ & $-20.1 * *$ & $-33.8 * * *$ & $-17.5^{* *}$ \\
\hline & $(7.41)$ & $(8.21)$ & $(11.1)$ & $(7.60)$ \\
\hline \multirow[t]{2}{*}{ Female } & $10.7^{*}$ & $12.2^{* *}$ & -3.45 & 5.30 \\
\hline & $(5.57)$ & $(5.87)$ & $(10.5)$ & $(5.51)$ \\
\hline \multirow[t]{2}{*}{ Female $\mathrm{x}$ VOC } & & & 23.1 & \\
\hline & & & $(15.7)$ & \\
\hline \multirow[t]{2}{*}{ Female x VOCPT } & & & 13.4 & \\
\hline & & & $(15.9)$ & \\
\hline \multirow[t]{2}{*}{ Female x PT } & & & $28.0 *$ & \\
\hline & & & $(15.0)$ & \\
\hline \multirow[t]{2}{*}{ Cutoff in Round 3} & $0.63 * * * *$ & $0.64 * * * *$ & $0.64 * * * *$ & $0.61 * * * *$ \\
\hline & $(0.047)$ & $(0.048)$ & $(0.048)$ & $(0.044)$ \\
\hline \multirow[t]{2}{*}{ Guessed Rank in Round 3} & $10.7 * *$ & $8.54^{*}$ & $8.73^{*}$ & $-20.1 * * * *$ \\
\hline & $(4.48)$ & $(4.68)$ & $(4.72)$ & $(5.88)$ \\
\hline \multirow[t]{2}{*}{ Guessed Rank in Round 4} & & & & $40.1 * * * *$ \\
\hline & & & & $(5.58)$ \\
\hline Controls & No & Yes & Yes & Yes \\
\hline Constant & $84.6^{* * * *}$ & 3820 & 4070 & 2658 \\
\hline $\mathrm{R}^{2}$ & 0.593 & 0.614 & 0.619 & 0.670 \\
\hline Observations & 322 & 322 & 322 & 322 \\
\hline
\end{tabular}

Notes: Controls are a dummy for being a current undergraduate student, year of birth, major, whether or not the participant has played competitive sports, session size, share women in the session, and dummy for whether participant participated in a session with four minutes (not five) to solve problems. Included but not displayed are scores in Rounds $1-3$. Standard errors in parentheses. $*$ indicates significance at $10 \%, * *$ at $5 \%, * * *$ at $1 \%, * * * *$ at $0.1 \%$. These results are unchanged if alternative performance controls are used (only Round 1 Score, or only Round 1 and Round 2 score); results available upon request.

Thus, sponsorship, in the form that we provide, fails to close the gender gap in willingness to compete. Recall that in Round 3, the average cutoff among men was 16 cents less than the cutoff among women ( $\mathrm{p}=0.052$ ). This gap is similar in Round 4 among Unsponsored participants (falling slightly to 13 cents). On the other hand, the gender gap in cutoffs increases in Round 4 for all of our sponsorship conditions - to 37 cents in VOC, to 27 cents in VOCPT, and to 44 cents in PT. Because it primarily increases competitiveness among male protégés, sponsorship does not close the gender gap. 


\section{How Sponsorship Impacts Beliefs}

Our VOC treatments may positively impact participant beliefs. In particular, we might expect that being told that one has been chosen to be sponsored would weakly increase a participant's belief of relative ability. For participants close to the margin, i.e. those whose believed rank is in the neighborhood of the top 25\%, being sponsored may provide a nudge toward competing. Here, we explore how our sponsorship treatments impact beliefs.

We start by documenting participant beliefs in Round 3. In Table 4, we display the predicted and actual distributions over quartiles for men and women in Round $3 .{ }^{24}$ Recall that participants are being asked to guess where their Round 3 score will place them relative to all Round 2 scores. Nearly 55\% of men believe that their Round 3 performance will place them in the top 25\% of performers, while only $34 \%$ of women make this prediction ( $p$-value test of proportions, $p<0.001$ ). The significant gender gap in self-confidence persists when we control for ability. If we regress believed quartile rank in Round 3 on gender, performance in Rounds 1 through 3, and our other controls, we estimate that women submit believed ranks 0.26 places worse than men ( $\mathrm{p}$ value $<0.001$ ). On average, both men and women are overconfident: $47 \%$ of men and $45 \%$ of women predict a better performance than they actually deliver.

Table 4. Distributions of Believed and Actual Round 3 Rank by Gender

\begin{tabular}{|c|c|c|c|c|c|c|}
\hline & \multicolumn{3}{|c|}{ Believed Quartile Ranks } & \multicolumn{3}{|c|}{ Actual Quartile Ranks } \\
\hline & Men & Women & $\mathrm{p}$ value & Men & Women & $\mathrm{p}$ value \\
\hline Top Quartile & $55 \%$ & $34 \%$ & & $38 \%$ & $26 \%$ & \\
\hline Second Quartile & $34 \%$ & $45 \%$ & & $24 \%$ & $29 \%$ & \\
\hline Third Quartile & $9 \%$ & $15 \%$ & & $20 \%$ & $28 \%$ & \\
\hline Bottom Quartile & $2 \%$ & $6 \%$ & & $18 \%$ & $17 \%$ & \\
\hline Mean Quartile Rank & 1.59 & 1.93 & $<0.001$ & 2.18 & 2.35 & 0.11 \\
\hline
\end{tabular}

Both VOC treatments have a significant, positive impact on beliefs. Compared to the change in beliefs between Rounds 3 and 4 in the Unsponsored treatment, participants in the VOC treatment rank themselves 0.2 quartiles better after the intervention $(\mathrm{p}=0.005)$ and participants in the VOCPT treatment rank themselves 0.17 quartiles better $(\mathrm{p}=0.03$ ). These changes in beliefs are very similar for men and

\footnotetext{
${ }^{24}$ Note that participants are being compared to the performance distribution in Round 2; thus, improvement across rounds will lead to greater representation of participants in the top quartiles. Most of this improvement seems to happen between Rounds 2 and 3. The mean rank of a participant in Round 2 is 2.35; the mean rank of a participant in Round 3 is 2.27 ( $p<0.10$ ). After Round 3 our interventions occur, so it is hard to separate the impact of improvement and sponsorship for participants in our sponsorship treatments. Therefore, we rely on our Unsponsored participants to estimate the improvement that would occur between Rounds 3 and 4 absent our intervention. Among these participants, there is no change in rank between Rounds 3 and 4: mean rank in Round 3 is 2.31 and mean rank in Round 4 is $2.34(\mathrm{p}=0.78)$. Recall these ranks are computed by comparing current round performance to Round 2 performances.
} 
women. In the PT treatment, there is no significant change in the beliefs of participants. In Online Appendix Table A5, we present regressions that show the full set of effects of sponsorship on beliefs.

In Specification IV of Table 3, we ask how much of the treatment effects are driven by these changes in beliefs. Recall that we ask participants to guess where they will rank, in an incentivized way, both in Rounds 3 and 4 . We include the Round 3 guess in all specifications as a control. Including the Round 4 guess allows us to ask whether the treatments are operating through changing participant beliefs. If the effects of the treatments are explained by beliefs, we should see a large and significant coefficient on Round 4 guess of rank when it is added to the specification and largely reduced coefficients on the treatments. What we find is that beliefs do matter, but they do not entirely explain the effect of the treatments. Reassuringly, changes in beliefs explain a larger share of the treatment effects in those treatments where protégés are chosen rather than randomly-assigned (VOC and VOCPT) than in the PT only treatment. Changes in beliefs explain $38 \%$ of the treatment effect in the VOC treatment, $27 \%$ of the VOCPT treatment effect, and 13\% of the PT treatment effect. ${ }^{25}$ In Online Appendix Section IV, we provide additional analysis on how the effects of sponsorship vary with the baseline confidence of the participant. Contrary to what program designers might hope, sponsorship seems to be most effective among overconfident participants, particularly overconfident men.

\section{E. How Sponsorship Impacts Performance}

Next, we turn our attention to the impact of sponsorship on performance. In Table 5, we predict Round 4 performance (number of correct problems solved) from treatment and performance in past rounds. In the first specification, we control only for past performances and gender; Specification II adds demographic and session-specific controls. In Specification III, we add the interactions of gender with treatment. Finally, in Specification IV, we include beliefs of Round 4 performance, testing for the possibility that any treatment effect on performance operates through changes in beliefs.

Table 5. Regression Analysis of Performance in Round 4

\begin{tabular}{llllc}
\hline & \multicolumn{5}{l}{ OLS Predicting Performance in Round 4 } \\
\hline Specification & I & II & III & IV \\
\hline \multirow{2}{*}{ VOC } & & & & \\
& 0.32 & 0.21 & 0.20 & 0.16 \\
VOCPT & $(0.32)$ & $(0.33)$ & $(0.46)$ & $(0.46)$ \\
& 0.37 & 0.38 & 0.65 & 0.58 \\
& $(0.33)$ & $(0.34)$ & $(0.48)$ & $(0.49)$
\end{tabular}

\footnotetext{
${ }^{25}$ In Appendix VI, Appendix Table A13, we show that these results are robust to using guessed rank dummies, rather than a linear control for guessed rank. In the version of Specification IV using guessed rank dummies, we estimate that changes in beliefs explain $44 \%$ of the treatment effect in the Vote of Confidence treatment, $32 \%$ of the treatment effect in the Vote of Confidence \& Payment-Tying treatment, and $16 \%$ of the treatment effect in the Payment-Tying treatment.
} 


$\begin{array}{llllc} & 0.97 * * * & 0.92^{* * *} & 1.39 * * * & 1.37 * * * \\ \text { PT } & (0.31) & (0.35) & (0.47) & (0.47) \\ \text { Female } & -0.74^{* * *} & -0.75^{* * *} & -0.38 & -0.28 \\ \text { Female x VOC } & (0.23) & (0.24) & (0.44) & (0.45) \\ \text { Female x VOCPT } & & -0.01 & -0.08 \\ & & (0.66) & (0.66) \\ \text { Female x PT } & & -0.56 & -0.54 \\ & & (0.68) & (0.67) \\ \text { Guessed Rank Rd. 4 } & & -0.93 & -0.91 \\ & & & (0.64) & (0.64) \\ \text { Controls } & & & -0.25 \\ \text { Constant } & & & (0.17) \\ \mathrm{R}^{2} & & & \text { Yes } \\ \text { Observations } & \text { No } & \text { Yes } & 31.5 & 43.6 \\ \text { Cos } & 0.92^{* *} & 26.0 & 0.777 & 0.778 \\ & 0.770 & 0.774 & 322 & 322\end{array}$

Notes: Controls are a dummy for being a current undergraduate student, year of birth, major, whether or not the participant has played competitive sports, session size, share women in the session, and dummy for whether participant participated in a session with four minutes (not five) to solve problems. Included but not displayed are scores in Rounds $1-3$. Standard errors in parentheses. * indicates significance at $10 \%, * *$ at $5 \%, * * *$ at $1 \%, * * * *$ at $0.1 \%$.

We find that, overall, sponsorship has a weakly positive effect on Round 4 performance. We estimate that, conditional on past performance, being assigned to the PT treatment increases performance by approximately 0.92 problems in Round $4(\mathrm{p}<0.01)$. The two other sponsorship treatments produce only directional increases in performance. The third column documents that the impact of sponsorship on performance is directionally larger for men than women. We estimate performance increases of 0.20 problems, 0.65 problems, and 1.39 problems for men in the VOC, VOCPT treatment, and PT treatments, respectively. Only the PT treatment increase is significant $(\mathrm{p}=0.003)$. For women, we estimate increases of 0.18 (SE 0.48), 0.10 (SE 0.47), and 0.46 problems (SE 0.47) in the VOC, VOCPT treatment, and PT treatments, respectively. None of the increases in female performance are significant.

There are two reasons why we might expect performance to increase under sponsorship. The first is that participants who are chosen have more optimistic beliefs relative to Unsponsored participants; thus, they may forecast a higher return to their performance because of a larger perceived chance of placing in the top 25\%. Our results suggest that this force is not large: men and women in the VOC treatment do not increase their performance significantly. And, in Column IV, we show that the estimated treatment effects on performance are not explained by changes in beliefs; adding believed rank in Round 4 does not alter any of the estimated treatment effects. The other motivation for increased performance stems from the payment-tying channel: now a successful performance benefits not only the protégé but also the sponsor. If participants have other-regarding preferences, the PT treatments may encourage more effort. This motivation seems to have more support in the data: men increase their performance in the PT 
treatment. The increase in performance under the VOCPT treatment is not significantly different than 0; however, we also cannot reject that the coefficients on the two PT treatments are the same.

\section{F. Whom Does Sponsorship Impact?}

A natural next question to ask is how the effects of sponsorship vary with the ability of the participant. Increasing one's willingness to compete is only beneficial (in terms of earnings) if the participant places in the top $25 \%$ of performers. We would like to understand whether sponsorship is, at least on average, pushing people toward making better decisions about compensation scheme.

In Table 6, we ask whether the effects of sponsorship vary with participant ability. To increase our statistical power, we pool the three sponsorship treatments and use a single "sponsored" dummy. We predict willingness to compete in Round 4 conditional on past performance and cutoff in Round 3, and we include dummies for the participant's quartile rank in Round 3, interacted with the sponsorship dummy. We do this separately for each gender. For ease of interpretation, we simply provide the estimated effects of sponsorship split by Round 3 performance quartile and gender. ${ }^{26}$ Sponsorship has the largest effects on men in the bottom two quartiles of the distribution. And, controlling for performance, sponsorship is directionally more effective for men than women in every quartile. ${ }^{27,}{ }^{28}$ Thus, sponsorship is less effective for what is arguably the target population: high-ability performers who would earn more by competing.

Table 6. Increases in Willingness to Compete by Quartiles of Participant Ability under Sponsorship

\begin{tabular}{lll}
\hline & Men & Women \\
\hline Top Quartile & 13.5 & 11.3 \\
& {$[11.6]$} & {$[19.8]$} \\
Second Quartile & $38.9 * *$ & 20.5 \\
& {$[16.9]$} & {$[20.3]$} \\
Third Quartile & $68.9 * * * *$ & 21.0 \\
& {$[17.8]$} & {$[18.5]$} \\
Bottom Quartile & $56.9 * * *$ & -7.8 \\
& {$[18.6]$} & {$[23.7]$} \\
\hline
\end{tabular}

Notes: We estimate these effects using the regression in Specifications II and IV in Appendix Table A13, but we replace sum of first 3 scores with Round 3 rank. We interact Round 3 rank with our sponsorship dummy. This table displays the estimated total

\footnotetext{
${ }^{26}$ In Online Appendix Table A13, we present the full regression results that interact each separate treatment with a continuous measure of participant ability (sum of first three scores).

${ }^{27}$ One could also consider the optimality of choices made by participants. One measure of optimality is what fraction of participant choices would be profit-maximizing given their realized performance in the round. In Round 3, 57.6\% of participant choices are profit-maximizing ex post given performance. In general, sponsorship is decreasing the fraction of optimal choices: by an estimated 5 percentage points in the Vote of Confidence treatment (n.s.), 13 percentage points in the Vote of Confidence and Payment-Tying treatment $(\mathrm{p}<0.01)$, and by 8 percentage points in the Payment-Tying treatment $(\mathrm{p}<0.10)$. Most of this is driven by lower ability participants, who do not place among the top $25 \%$, choosing to compete more often.

${ }^{28}$ One concern is that high ability participants may face a censoring problem, as cutoffs may already have been low in Round 3. Average cutoffs by quartile in Round 3 are 164, 201, 207, and 228. If we exclude participants who had already had the minimum cutoff in Round 3, results are directionally unchanged (results available upon request). And, in Appendix VI, we show that all of these results are robust to including score fixed effects. Finally, in Appendix III, we show that these results are unchanged if sum of first two scores are used as a control for past performance rather than sum of first three scores.
} 
coefficient on the pooled sponsorship dummy for each of the four quartiles. Standard errors in parentheses. * indicates significance at $10 \%, * *$ at $5 \%, * * *$ at $1 \%, * * * *$ at $0.1 \%$. These results are unchanged if alternative performance controls are used (only Round 1 Score, or only Round 1 and Round 2 score); results available upon request.

\section{G. The Effect of Sponsorship on Earnings}

Sponsorship increases the number of competitive choices, particularly by low ability men. However, we have seen that sponsorship also seems to at least directionally increase performance among men. A natural question to ask is how these two forces combine to impact earnings. Holding fixed performance, more competitive choices by low ability men should deflate earnings. But, if performance increases enough, earnings could rise - either through pushing more individuals into the top $25 \%$ of performers or by increasing earnings under those wages for which the participant chose the piece-rate compensation. ${ }^{29}$

In Table 7, we use regression analysis to explore the changes in earnings. We predict a participant's earnings in Round 4 from her treatment, her gender, her earnings in Round 3, and her scores in Rounds 1 - 3. In Specification I, we see that the VOC and PT treatments directionally increase earnings in Round 4 relative to the Unsponsored treatment; the increase in the VOC treatment is approximately 140 cents (n.s.) and the increase in the PT treatment is 211 cents $(\mathrm{p}<0.10)$. The VOCPT treatment has no effect on earnings. In Specification III, we ask whether the impact on earnings differs by gender. Again, the data are quite noisy; if anything, they suggest that sponsorship has a directionally smaller effect on women.

Next, we attempt to decompose the effects of the two factors that determine earnings: performance and competitive preferences. Given that we know most of the increase in competitiveness is coming from low ability men, we expect that any positive effect on earnings of our sponsorship treatments is being driven by increases in performance. In Specifications IV and V, we add performance in Round 4 to the specification, which captures any impact of the treatments on performance. Thus, the coefficients on the treatments in these specifications should be interpreted as the impact on earnings attributable to changes in choices over compensation scheme. While our data are noisy, these specifications suggest that the earnings gains accrued by men are largely due to changes in performance. In particular, the significant, positive effect of the PT treatment on the earnings of men is erased once we condition on performance in Round 4. It does not appear that sponsorship is pushing participants toward making better compensation scheme choices. If it were, we would expect to see a positive effect on earnings attributable to compensation scheme choice (positive coefficients on treatments in Specifications IV and V).

Table 7. The Effect of Sponsorship on Earnings in Round 4

\footnotetext{
${ }^{29}$ We could also frame the problem the other way. Holding fixed competitive choices, an increase in performance by low ability men should increase earnings: the participant will earn strictly more at all wages for which he chose piece-rate compensation and will observe a weakly positive increase at wages for which he chose the tournament ( 0 change if the performance increase does not place him in the top 25\%; a large positive change if the performance increase does place him in the top 25\%). The question in these terms is then whether the male participants made enough non-optimal competitive choices to offset the earnings increase that results from their increase in performance.
} 


\begin{tabular}{|c|c|c|c|c|c|}
\hline \multicolumn{6}{|c|}{ OLS Predicting Earnings in Round 4} \\
\hline Specification & I & II & III & IV & $\mathrm{V}$ \\
\hline VOC & $\begin{array}{c}140.1 \\
(117.0)\end{array}$ & $\begin{array}{c}106.4 \\
(119.8)\end{array}$ & $\begin{array}{c}152.1 \\
(166.9)\end{array}$ & $\begin{array}{c}46.4 \\
(92.9)\end{array}$ & $\begin{array}{c}96.2 \\
(129.2)\end{array}$ \\
\hline VOCPT & $\begin{array}{c}4.44 \\
(120.1)\end{array}$ & $\begin{array}{c}6.62 \\
(122.3)\end{array}$ & $\begin{array}{c}192.5 \\
(175.8)\end{array}$ & $\begin{array}{l}-109.7 \\
(95.1)\end{array}$ & $\begin{array}{c}13.1 \\
(136.6)\end{array}$ \\
\hline PT & $\begin{array}{l}211.6 * \\
(114.3)\end{array}$ & $\begin{array}{l}215.9 * \\
(126.4)\end{array}$ & $\begin{array}{c}280.8 \\
(170.7)\end{array}$ & $\begin{array}{l}-16.5 \\
(99.2)\end{array}$ & $\begin{array}{c}-54.3 \\
(134.1)\end{array}$ \\
\hline Female & $\begin{array}{c}-149.5^{*} \\
(84.2)\end{array}$ & $\begin{array}{c}-19.7^{* *} \\
(88.7)\end{array}$ & $\begin{array}{c}-51.8 \\
(160.9)\end{array}$ & $\begin{array}{l}-29.9 \\
(69.6)\end{array}$ & $\begin{array}{c}28.6 \\
(124.7)\end{array}$ \\
\hline Female $x$ VOC & & & $\begin{array}{c}-113.2 \\
(239.5)\end{array}$ & & $\begin{array}{l}-110.0 \\
(185.3)\end{array}$ \\
\hline Female $\mathrm{x}$ VOCPT & & & $\begin{array}{l}-359.1 \\
(244.6)\end{array}$ & & $\begin{array}{l}-230.2 \\
(189.5)\end{array}$ \\
\hline Female x PT & & & $\begin{array}{l}-149.4 \\
(230.6)\end{array}$ & & $\begin{array}{c}55.8 \\
(179.0)\end{array}$ \\
\hline Earnings in Round 3 & $\begin{array}{c}0.62^{* * * * *} \\
(0.06)\end{array}$ & $\begin{array}{c}0.58 * * * * \\
(0.07)\end{array}$ & $\begin{array}{c}0.58 * * * * \\
(0.07)\end{array}$ & $\begin{array}{c}0.47 * * * * \\
(0.05)\end{array}$ & $\begin{array}{c}0.47^{* * * * *} \\
(0.05)\end{array}$ \\
\hline Round 4 Score & & & & $\begin{array}{c}231.5^{* * * * *} \\
(16.2)\end{array}$ & $\begin{array}{c}231.9 * * * * \\
(16.3)\end{array}$ \\
\hline Controls & No & Yes & Yes & Yes & Yes \\
\hline Constant & $-510 * * *$ & -23438 & -25943 & -25977 & -29737 \\
\hline $\mathrm{R}^{2}$ & 0.68 & 0.68 & 0.69 & 0.81 & 0.81 \\
\hline Observations & 322 & 322 & 322 & 322 & 322 \\
\hline
\end{tabular}

Notes: Controls are a dummy for being a current undergraduate student, year of birth, major, whether or not the participant has played competitive sports, whether participant was in a four minute session, session size, and share women in session. Included but not displayed are Round $1-3$ scores. Standard errors in parentheses. * indicates significance at $10 \%, * *$ at $5 \%$, *** at $1 \%$, $* * * *$ at $0.1 \%$. These results are unchanged if alternative performance controls are used (only Round 1 Score, or only Round 1 and Round 2 score); results available upon request.

\section{Discussion}

The business model of contemporary professional services firms requires the recruitment, retention and advancement of talented professional staff. The public accounting industry provides a powerful illustration of the challenges posed by this model: women comprise approximately half of the graduates 
earning degrees but less than $20 \%$ of firm partners. Firm management and scholars have suggested that sponsorship programs are an effective tool for female professionals seeking advancement within the organization.

Our experiment evaluates two aspects of sponsorship -- its vote of confidence and its link to compensation. We find, contrary to what is likely intended, that both features increase men's willingness to compete, particularly low-ability men, while neither significantly increases women's willingness to compete on average. We also see some evidence that men's performance improves under sponsorship, while women's does not. Rather than closing the gender gap in competition or compensation, sponsorship perpetuates the gap on average.

More broadly, our results speak to the stubbornness of the gender gap in willingness to compete in male-typed tasks. The two nudges we provide are ineffective at increasing competitiveness among women. While other laboratory studies have documented that the provision of informative signals of own and others' abilities can reduce the gender gap in competitiveness, our less precise form of feedback being chosen to be sponsored - is not successful. Because organizations may often lack the capacity to precisely evaluate or credibly communicate information on relative ability, understanding how these more informal forms of feedback operate on the beliefs and decisions of workers is an important step in designing effective and implementable programs.

In practice, sponsorship is a resource intensive program, as a limited number of partners are able to sponsor a finite set of professional staff. We observe the largest effects of sponsorship among less talented male protégés, a group that may be unlikely to be sponsored in the field. Of course, precisely identifying the highest-ability employees may prove more challenging outside of the laboratory, and many firms offer sponsorship opportunities to a diverse set of candidates. Thus, documenting the heterogeneous effects of sponsorship is important for understanding how these programs may impact outcomes in the field.Our results provide insights into ways that sponsorship may influence protégées’ willingness to compete. Our experiment focused on the vote of confidence being sponsored provides and on the linkage of sponsor and protégé payments. By restricting the nature of the relationship between the sponsor and the protégé, we were able not only to isolate two key features of sponsorship, but also to completely control the nature of the interaction - assuring that male and female protégés were treated identically by their sponsors. This limited interaction was useful for our analysis, but precludes us studying how a more complex, long-term sponsorship relationship might benefit young professionals outside of the lab. Future research could explore the nature or influence of these relationships or could more fully investigate the impact of these types of opportunities on those not chosen for sponsorship. Careful field evaluations of sponsorship programs could also provide invaluable evidence both for academics and policy makers searching for ways to promote female advancement in competitive careers. 


\section{References}

AICPA Students, Academics and Inclusion, 2015 Trends in Supply and Demand, American Institute of Certified Public Accountants, New York, NY, 2015.

Balafoutas, Loukas and Matthias Sutter, “Affirmative Action Policies Promote Women and Do Not Harm Efficiency in the Laboratory”, Science, 2012, Vol. 335, pp. 579-582.

Baldiga, Nancy, Promoting Your Talent: A Guidebook for Women and their Firms, American Institute of Certified Public Accountants, New York, NY, 2004.

Bertrand, Marianne, Claudia Goldin, and Lawrence Katz, "Dynamics of the Gender Gap for Young Professionals in the Financial and Corporate Sectors," American Economic Journal: Applied Economics, 2 (2010), pp. $228-255$.

Buser, Thomas, Muriel Niederle and Hessel Oosterbeek, "Gender, Competitiveness and Career Choices," forthcoming, Quarterly Journal of Economics, 2014, Vol. 129, No. 3, pp. 1409-1447.

Carter, Chris, Crawford Spence, and Claire Dambrin, “Qualities of a Big 4 Partner,” Economia, July, 2014. (http://economia.icaew.com/finance/july-2014/essay-the-qualities-of-a-big-four-partner”)

Cason, Timothy N., William A. Masters, and Roman M. Sheremeta, "Entry into Winner-Take-All and Proportional-Prize Contests: An Experimental Study”, Journal of Public Economics, 94, pp. 604 - 611.

Cooper, David and John Kagel, “Other-regarding Preferences: A Selective Survey of Experimental Results," to appear in the Handbook of Experimental Ecnomics, Vol. 2, edited by John Kagel and Alvin Roth, Princeton University Press.

Croson, Rachel and Uri Gneezy, "Gender Differences in Preferences, Journal of Economic Literature, 2009, Vol. 47:2, pp. 1 - 27.

Dreber, Anna, Emma von Essen, and Eva Ranehill, "Gender and Competition in Adolescence - Tasks Matter," Forthcoming in Experimental Economics.

Ertac, Seda and Balazs Szentes, “The effect of information on gender differences in competitiveness: experimental evidence”, Working paper, 2010, Koc University.

Feintzeig, Rachel, "More Companies Say Targets are the Key to Diversity,” The Wall Street Journal, September 30, 2015. (http://www.wsj.com/articles/more-companies-say-targets-are-the-key-to-diversity1443600464)

Foust-Cummings, Heather, Sarah Dinolfo and Jennifer Kohler, Sponsoring Women to Success, Catalyst, New York, NY, 2011.

Gneezy, Uri, and Aniela Pietrasz, “On the Size of the Gender Difference in Competitiveness,” Working paper, 2014, University of San Diego Rady School of Business.

Gneezy, Uri and Aldo Rustichini, "Gender and Competition at a Young Age,” American Economic Review Papers and Proceedings, 2004, Vol. 94, pp. 377 - 381. 
Gneezy, Uri, Muriel Niederle, and Aldo Rustichini, "Performance in Competitive Environments: Gender Differences,” Quarterly Journal of Economics, 2003, Vol. 118, No. 3, pp. 1049-1074.

Goldin, Claudia, “A Grand Gender Convergence: Its Last Chapter,” American Economic Review, 104 (2014), pp. 1 - 30.

Grosse, Niels and Gerhard Riender, "Explaining Gender Differences in Competitiveness: Gender-task Stereotypes,” Working paper, 2010.

Hewlett, Sylvia Ann, “As You Start Your Career, Focus on Your People Skills,” Blog Post, Harvard Business Review, April 2014. (https://hbr.org/2014/04/as-you-start-your-career-focus-on-people-skills)

Hewlett, Sylvia Ann, Forget a Mentor, Find a Sponsor, Harvard Business Review Press, Boston, MA, 2013.

Hewlett, Sylvia Ann, with Kerrie Peraino and Laura Sherbin, “The Sponsor Effect: Breaking Through the Last Glass Ceiling,” Harvard Business Review Research Report, Harvard Business School Publishing, 2010.

Ifcher, John and Homa Zarghamee, "Pricing Competition: A New Laboratory Measure of Gender Differences in the Willingness to Compete,” 2014, Working paper, Santa Clara University.

Kamas, Linda and Anne Preston, “Are Women Really Less Competitive than Men?”, Working paper, 2010.

LeanIn.Org and McKinsey \& Company, "Women in the Workplace 2015," http://womenintheworkplace.com/ui/pdfs/Women_in_the_Workplace_2015.pdf?v=5

Niederle, Muriel, and Lise Vesterlund, "Do Women Shy Away from Competition? Do Men Compete too Much?,” Quarterly Journal of Economics, 2007, Vol. 122, No. 3, 1067-1101.

Niederle, Muriel, Carmit Segal, and Lise Vesterlund, "How Costly is Diversity? Affirmative Action in Light of Gender Differences in Competitiveness”, Management Science, 2013, Vol. 59, No. 1, pp. 1 - 16.

Petrie, Ragan and Carmit Segal, “Gender Differences in Competitiveness: The Role of Prizes”, 2014, Working paper.

Shurchkov, Olga, “Under Pressure: Gender Differences in Output Quality and Quantity Under Competition and Time Constraints," Journal of the European Economic Association, 2012, Vol. 10, pp. $1189-1213$.

Tonin, Mirco and Michael Vlassopoulos, "Social Incentives Matter: Evidence from an Online Real Effort Experiment,” working paper, 2012.

Tonin, Mirco and Michael Vlassopoulos, "Disentangling the Sources of Pro-socially Motivated Effort: A Field Experiment,” Journal of Public Economics, 2010, Vol. 94, Issue 11-12, pp. 1086 - 1092.

Wozniak, David, William T. Harbaugh, and Ulrich Mayr, “The Menstrual Cycle and Performance Feedback Alter Gender Differences in Competitive Choices”, Journal of Labor Economics, 2014, Vol. 32, No. 1, pp. $161-198$. 